\title{
Factors Associated With Influential Health-Promoting Messages on Social Media: Content Analysis of Sina Weibo
}

Qingmao Rao ${ }^{1,2}$, MA; Zuyue Zhang ${ }^{1,2}$, MA; Yalan $\mathrm{Lv}^{1}$, PhD; Yong Zhao ${ }^{3}$, PhD; Li Bai ${ }^{4}$, MA; Xiaorong Hou ${ }^{1,2}$, MA

${ }^{1}$ College of Medical Informatics, Chongqing Medical University, Chongqing, China

${ }^{2}$ Medical Data Science Academy, Chongqing Medical University, Chongqing, China

${ }^{3}$ School of Public Health and Management, Chongqing Medical University, Chongqing, China

${ }^{4}$ Hospital of Zigong Mental Health Central, Zigong, China

\section{Corresponding Author:}

Xiaorong Hou, MA

College of Medical Informatics

Chongqing Medical University

No.1, Medical College Road

Yuzhong District

Chongqing, 400016

China

Phone: 8613883901680

Email: xiaoronghou@ cqmu.edu.cn

\section{Abstract}

Background: Social media is a powerful tool for the dissemination of health messages. However, few studies have focused on the factors that improve the influence of health messages on social media.

Objective: To explore the influence of goal-framing effects, information organizing, and the use of pictures or videos in health-promoting messages, we conducted a case study of Sina Weibo, a popular social media platform in China.

Methods: Literature review and expert discussion were used to determine the health themes of childhood obesity, smoking, and cancer. Web crawler technology was employed to capture data on health-promoting messages. We used the number of retweets, comments, and likes to evaluate the influence of a message. Statistical analysis was then conducted after manual coding. Specifically, binary logistic regression was used for the data analyses.

Results: We crawled 20,799 Sina Weibo messages and selected 389 health-promoting messages for this study. Results indicated that the use of gain-framed messages could improve the influence of messages regarding childhood obesity $(P<.001)$, smoking $(P=.03)$, and cancer $(P<.001)$. Statistical expressions could improve the influence of messages about childhood obesity $(P=.02)$, smoking $(P=.002)$, and cancer $(P<.001)$. However, the use of videos significantly improved the influence of health-promoting messages only for the smoking-related messages $(P=.009)$.

Conclusions: The findings suggested that gain-framed messages and statistical expressions can be successful strategies to improve the influence of messages. Moreover, appropriate pictures and videos should be added as much as possible when generating health-promoting messages.

(JMIR Med Inform 2020;8(10):e20558) doi: 10.2196/20558

\section{KEYWORDS}

health-promoting messages; social media; Sina Weibo; influence; framing effects; health communication

\section{Introduction}

\section{Overview}

Television, newspapers, radio, magazines, and other traditional media have long been the communication tools relied upon for health communication. More recently, social media, such as
Facebook, Twitter, and Sina Weibo (or Weibo), has gained explosive growth, especially in China [1]. As of June 2019, China has 854 million internet users, the vast majority of whom obtain information through social media [2]. An increasing number of scholars believe that social media has great potential as a tool in the field of health care [3] and health promotion $[4,5]$. 
Sina Weibo is one of the most popular social media platforms in China. In December 2018, this platform had 462 million active accounts, including more than 37,000 media organizations and 170,000 government agency accounts [6]. Yang et al [1] described Weibo as a mixture of features of Twitter and Facebook. Weibo also has some elements of a bulletin board system, blog, and social networking site. Social media has become a unique platform for health promotion due to its potential for viral messaging [7], its ability to challenge authority [8], and its diversity of users [9]. In China, Weibo has been widely used for health communication [10-12].

However, many health-promoting messages released on social media lack influence [13]. Health-promoting messages transmit health information through mass media to prevent diseases and promote health [14]. Van 't Riet et al [15] asserted that a health-promoting message should include health-related behaviors and the consequences of behaviors. As a result, health-promoting messages may contain terminologies and substantial expository text [16]. However, Chinese residents have low overall health information literacy [17]. Most people think that health messages on the internet are often too complex to understand [18]. The complex content in health-promoting messages hinders people's willingness to interact with them. Moreover, few studies have explored the effect of using specific communication strategies to enhance people's participation with health messages on social networking platforms [19].

Some strategies can improve the audience's acceptance of and participation with health messages. Myers [20] believed that health message-framing effects can be conducive to the spread of health-promoting messages and encourage people's health behaviors. Meppelink et al $[21,22]$ used pictures and videos in a health-promoting message to change the communication effect. Allen and Preiss [23] found that a statistical type of information organization made information more persuasive. Sundar [24] suggested that audiences are more likely to recognize information provided by professionals than by nonprofessionals. Social media has broken through the limitations of traditional media and made these strategies easier to use. A previous health information survey on child obesity [25] verified that framing effects could significantly change the audience's attitude toward information. Whether these strategies, especially the framing effects, contribute to the impact of health-promoting messages on the Weibo platform is worth studying.

Weibo has become one of the most notable platforms for people in China to seek health-promoting messages [26]. Examining the factors that shape the degree of influence of health-promoting messages on the Weibo platform is crucial. Many studies on health information dissemination have been carried out by questionnaires, but this technique has the problem of subjective bias. Therefore, this work employed a web crawler and manual coding to collect data from the real-world platform of Weibo. We considered the message-framing types as the influencing factors and explored whether the message sources, expression types, and use of pictures or videos would affect the degree of influence of health-promoting messages. The results of this study can guide the communication of related health themes and provide experimental evidence for theoretical

research related to the framing effects of health-promoting messages.

\section{Background}

\section{Message-Framing Effects}

Kahneman and Tversky [27] first proposed framing effects using the "Asian disease problem" example, thereby beginning the research on framing effects in the field of psychology. Message-framing effects for health-promoting messages have become a hot research topic. Prospect theory can explain framing effects. This theory holds that people can be acutely aware of whether a framing message emphasizes potential benefits or risks $[27,28]$. Health-promoting messages can be divided into gain-framed messages (which highlight the beneficial consequences of healthy behavior) or loss-framed messages (which underscore the detrimental counterpart) [15]. The gain- and loss-framed effects show that when health care messages emphasize the positive or negative results of an action or omission, the persuasiveness of the messages significantly differ. Previous studies have confirmed that a gain-framed message is effective in promoting the use of sunscreen and exercise activities [29]. Conversely, a loss-framed message is persuasive in promoting mammography, chest self-examination [30], and colorectal cancer detection [31]. Given the prior research [15] and the text-based message expression of Weibo [32], we posit that the gain-framed and loss-framed effects on health-promoting message dissemination on Weibo are similar to those of print media. A Weibo message that clearly expresses positive or negative consequences was regarded as framed.

\section{Expression Type and Visuals}

A statistical expression message refers to a missive that contains quantitative or numerical information [33]. Many studies have compared the persuasiveness of different types of information organization, especially the statistical and narrative evidence types, albeit with inconclusive results [34,35]. Allen and Preiss [23] believed that the use of statistical expressions in a highly technological world is crucial. Their meta-analysis also indicated that statistical expressions of proof are generally persuasive. A Weibo message that contains numerical evidence is considered a statistical expression message. Visuals [36] refer to adding descriptive pictures or videos to a Weibo message. Through literature review and the research completed by our group $[25,37]$, we found that visuals [38,39] and statistics [39] were two important message features that can be combined with framing effects to affect the influence of health messages. It is easy for users to detect pictures, videos, or precise numbers in Weibo messages, and it is also easy for message creators to add this content to Weibo messages.

\section{Evaluation Indicator of the Influence of Health-Promoting Messages in Weibo}

In our study, influence was defined as the degree to which a Weibo health-promoting message attracts users to participate in the message interaction, which also evaluates the effectiveness of health communication [40]. Shiratuddin et al [41] and Hassan and Shiratuddin [42] found that retweets, comments, and likes can reflect a user group's participation and attention to the content of Weibo messages. Retweets constitute the crucial 
mechanism of message diffusion on Weibo. Retweets are related to a variety of social motivations, such as spreading information to new audiences, pleasing specific audiences, publicly supporting someone, quoting others' views, and symbolizing friendship, loyalty, or respect. Starbird and Palen [43] believe that retweeting is a kind of information recommendation behavior. Comments and likes are the main ways for users to interact on Weibo. Comments on Weibo refer to users' personal opinions on a topic, according to their preferences and other subjective demands. A "like" button, represented by a thumbs up symbol, is present at the bottom of every post by the social network users. That symbol is clicked to express love and approval for a particular statement. The "like" option is easy to operate, thereby making the expression convenient and fast.

These 3 behaviors' costs mainly include time costs and credit costs. The time costs and credit costs for retweets, comments, and likes are different. Compared with the other two operations, the time costs and credit costs of the like operation are the lowest. The comment operation requires the highest time costs and some credit costs. The retweet operation requires few time costs and the highest credit costs. To summarize, we propose that when a Weibo message attracts users to participate in the interaction, the cost of commenting is the highest, retweeting is the second highest, and liking is the lowest. This means that the weights of likes (Lw), retweets $(\mathrm{Rw})$, and comments $(\mathrm{Cw})$ are different for the mathematical expression of the influence score. Therefore, the influence score (ls) of a Weibo message can be defined as the linear weighted sum of the number of retweets, comments, and likes. This can be expressed as:

$$
\begin{aligned}
& \mathrm{Is}=\alpha \mathrm{Lw}+\beta \mathrm{Rw}+\gamma \mathrm{Cw} \text { (1) } \\
& \alpha+\beta+\gamma=1 \text { (2) } \\
& \alpha<\beta<\gamma \text { (3) }
\end{aligned}
$$

Xiong et al [44] found that the number of retweets and comments had a positive correlation in a big data study on Weibo messages. The quantitative relationship between $\beta$ and $\gamma$ was obtained:

$$
\beta: \gamma=0.84 \text { (4) }
$$

Based on the data set of messages in the Weibo hot topic list, $\mathrm{Wu}$ [45] found the ratio of the number of likes to the sum of the number of retweets and comments in the Weibo messages in which users actively participated in the interaction. The quantitative relationship between $\alpha$ and $(\beta+\gamma)$ was obtained:

$$
\alpha:(\beta+\gamma)=0.25(\mathbf{5})
$$

The values of $\alpha, \beta$, and $\gamma$ can be obtained simultaneously with formulas 1,4 , and 5 :

$$
\text { Is }=0.2 \mathrm{Lw}+0.365 \mathrm{Rw}+0.435 \mathrm{Cw} \text {. }
$$

\section{Methods}

\section{Health Message Themes}

Because of the search method on Weibo, we first had to determine the keywords that could represent the health theme in order to search Weibo health messages. To identify health themes, we used the PubMed search engine, using "fram* effects" AND "health message*" as keywords, and obtained 229 papers. A panel of experts discussed health themes from these 229 papers. Through discussion, they found that obesity-related, smoking-related, and cancer-related health themes were mentioned more in the literature and that the public paid high attention to them. Combined with the previous research of our group [25], we ultimately chose "childhood obesity," "smoking," and "cancer" as keywords.

Using Python, we wrote a crawler program that could automatically obtain the fields in the Weibo platform according to the given keywords. The resulting fields included the message text, the publisher's name, and the number of retweets, comments, likes, pictures, and videos.

\section{Time Ranges of Health-Promoting Messages}

Weibo allows researchers to retrieve messages posted during a specified period through keyword searches. With childhood obesity, smoking, and cancer as the keywords, we retrieved posts for 1 month (November 1 to November 30, 2019). The 2 coders counted the number of health-promoting messages in the search posts and used the Cohen $\kappa$ coefficient to ensure the consistency between the coders. The statistics of the 2 coders revealed that the proportion of health-promoting messages containing the keywords was 1:4.4:5.1 (childhood obesity:smoking:cancer) (Figure 1). In order to ensure that the number of health-promoting messages in the 3 themes remained similar, we used childhood obesity as the keyword and searched for posts from January 1, 2019, to January 31, 2020 (13 months). Moreover, we employed smoking and cancer as the keywords and searched posts from November 1, 2019, to January 31, 2020 (3 months). 
Figure 1. Number of Weibo messages that contained the Chinese keyword in the Weibo database in November 2019. Health-promoting message content had to include health-related behaviors and the consequences of behaviors.

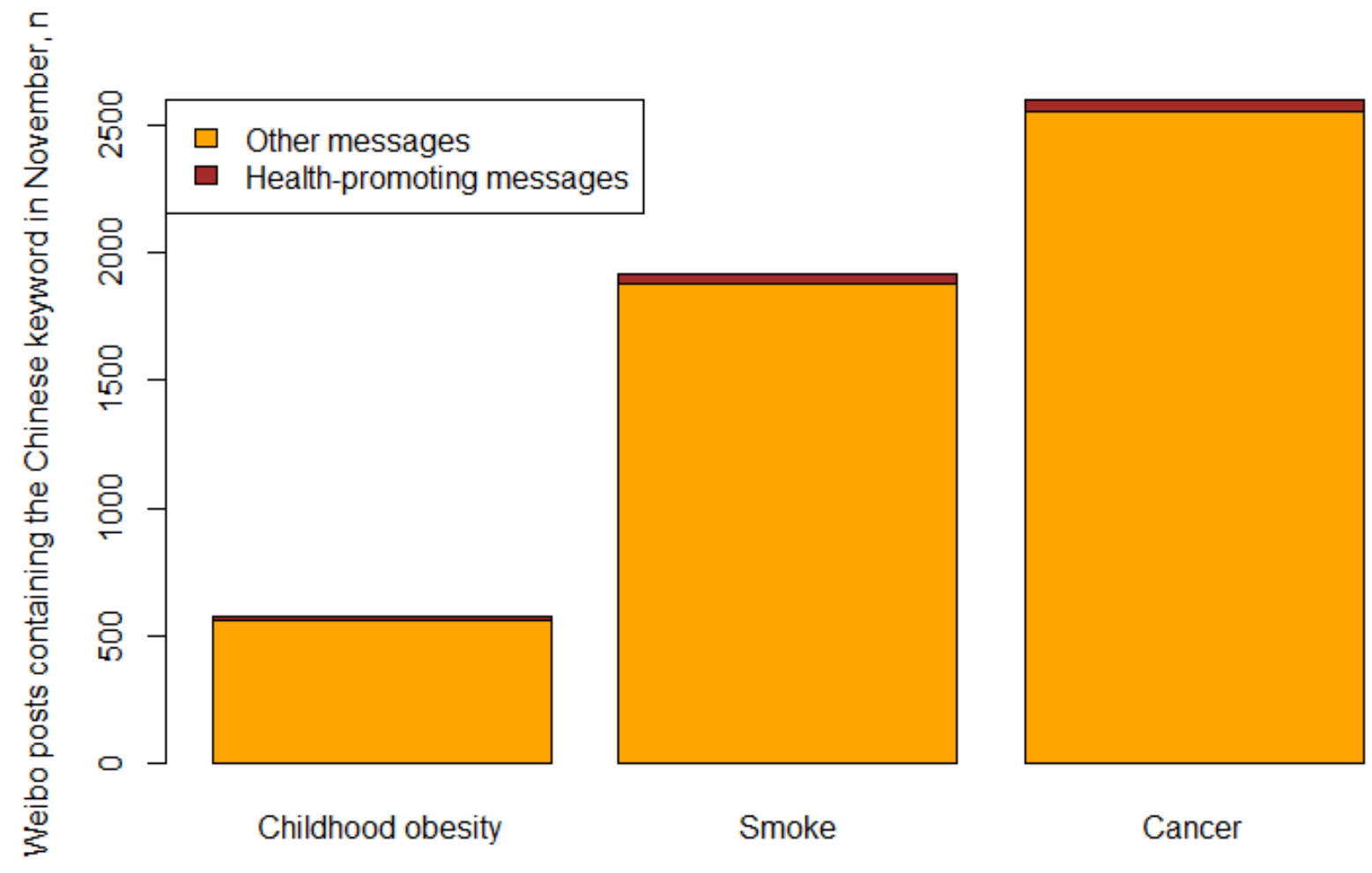

Keyword

\section{Coding of Health-Promoting Messages}

We used Python's Selenium library to simulate users' log-ins to Weibo's webpage by employing a written crawler code and using Weibo's advanced collection mechanism to search for messages with the keywords. The crawler was designed to output the search results, including the messages; the account names of the messages; the number of retweets, comments, and likes on messages; and any pictures or videos.

Two reviewers then screened the health-promoting messages from the search results according to the coding process (Figure
2) and coded the degree of influence, frame properties, influence source type, expression type, and presence of pictures and videos, as described in Multimedia Appendix 1 [9,31,45]. The 2 coders studied the coding principles carefully, and pre-experiment coding was carried out. In the pre-experiment coding, the 2 coders communicated effectively. Results that were similarly coded by the 2 reviewers could be entered directly. Messages with different codes were re-examined by a reviewer. Then, after eliminating human error, the coding was submitted to an expert group for judgment if the outcome was inconsistent. 
Figure 2. The coding process for the health-promoting messages.

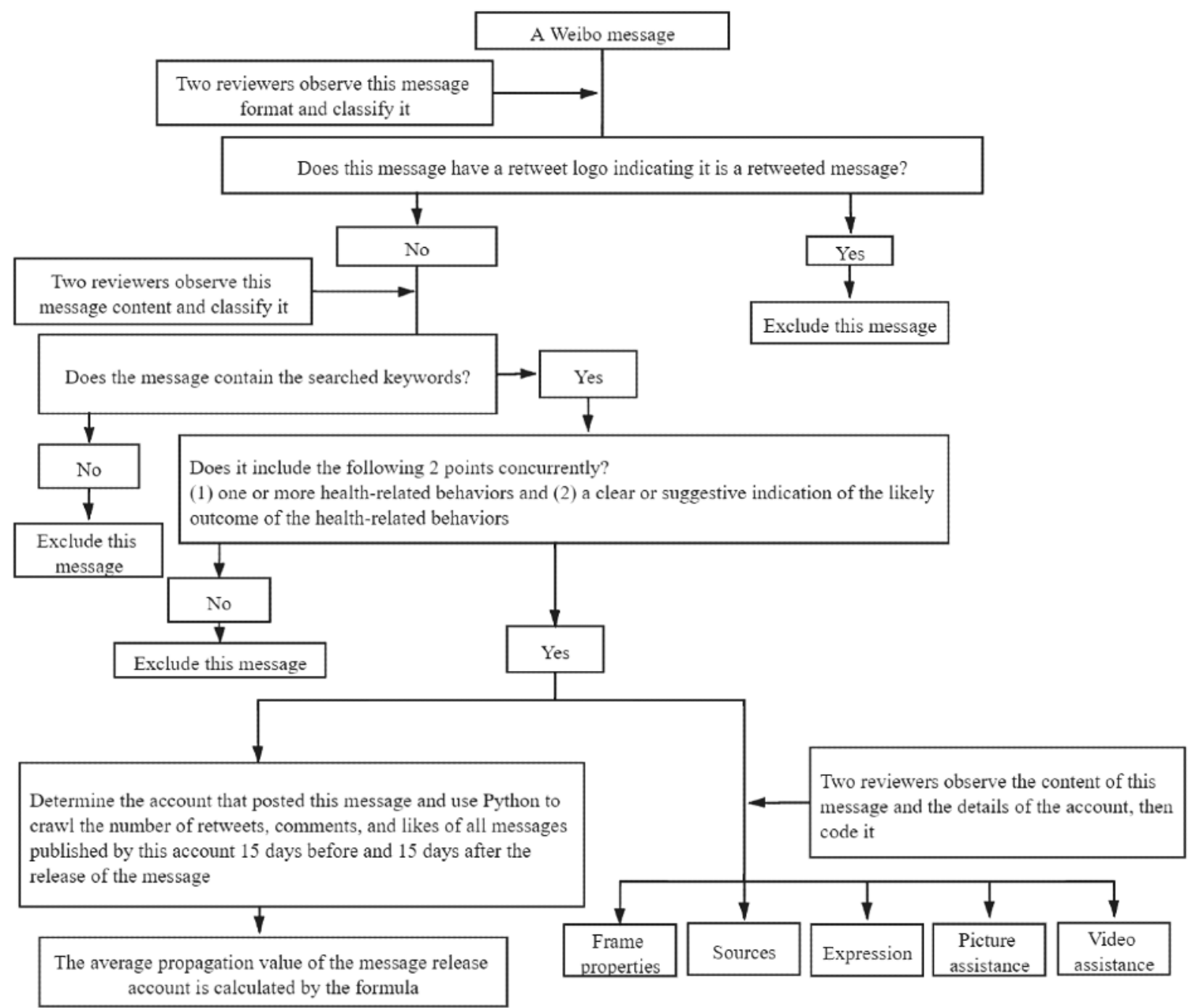

\section{Statistical Analysis}

Data were processed with Excel (Microsoft Corp) software before entry into the database. Data analyses were performed using SPSS 20.0 software (IBM Corp). Frequency and percentage were used to describe the categorical variables of the message characteristics. Binary logistic regression analysis was implemented to evaluate the influencing factors related to the health-promoting messages' influence. $P$ values below .05 were considered statistically significant.

\section{Quality Control}

Before the formal experiment, 2 coders randomly encoded 1800 Weibo messages. Cohen $\kappa$ was used to measure the consistency in SPSS 20.0. The Cohen $\kappa$ coefficient of the coders was 0.827 when judging whether a message was a health-promoting message, 0.962 when judging the influence of a health-promoting message, 0.859 when judging the frame properties of a health-promoting message, 0.943 when judging the expression properties of a health-promoting message, 0.977 when judging the sources of a health-promoting message, and 1.000 when judging whether a health-promoting message contained a picture or video. The two coders had good consistency and met the coding requirements of content analysis.

\section{Results}

\section{Descriptive Statistics of the Characteristics of Health-Promoting Messages}

A total of 389 health-promoting messages were included in this study (Table 1). Among these messages, 242 (62.1\%) were lower than the average influence score of the disseminator. The chosen items used loss-framed $(241 / 389,61.8 \%)$, gain-framed $(127 / 389,32.6 \%)$, and neutral-framed $(21 / 389,5.4 \%)$ messages. The disseminators of these health-promoting messages were mostly individual users, $31.3 \%$ (122/389) of whom possessed professional accounts certified by the platform or were labelled as engaged in the health field and 26.7\% (104/389) of whom were not certified by the platform nor labelled as engaged in the health field. Disseminators not from health institutions and organizations $(86 / 389,22.1 \%)$ outnumbered those from health institutions and organizations $(77 / 389,19.7 \%)$. A total of $44.1 \%$ (172/389) of the health-promoting messages contained statistical expressions. Furthermore, 51.3\% (200/389) of the health-promoting messages added corresponding pictures in addition to the text description. However, only $20.0 \%$ (78/389) of the messages added corresponding videos. 
Table 1. Descriptive statistics of characteristics of health-promoting messages.

\begin{tabular}{|c|c|c|c|c|}
\hline Variables & $\begin{array}{l}\text { Childhood obesity, } \\
\mathrm{n}(\%)(\mathrm{n}=128)\end{array}$ & $\begin{array}{l}\text { Smoking, } \mathrm{n}(\%) \\
(\mathrm{n}=114)\end{array}$ & $\begin{array}{l}\text { Cancer, } \mathrm{n}(\%) \\
(\mathrm{n}=147)\end{array}$ & $\begin{array}{l}\text { Total, n }(\%) \\
(\mathrm{N}=389)\end{array}$ \\
\hline \multicolumn{5}{|l|}{ Influence degree } \\
\hline High influence & $45(35.2)$ & $36(28.1)$ & $66(44.9)$ & $147(37.7)$ \\
\hline Low influence & $83(64.8)$ & $78(60.9)$ & $81(55.1)$ & $242(62.1)$ \\
\hline \multicolumn{5}{|l|}{ Frame properties } \\
\hline Loss framed & $74(57.8)$ & $94(73.4)$ & $73(49.7)$ & $241(61.8)$ \\
\hline Gain framed & $48(37.5)$ & $17(13.3)$ & $62(42.2)$ & 127 (32.6) \\
\hline Neutral framed & $6(4.7)$ & $3(2.3)$ & $12(8.2)$ & $21(5.4)$ \\
\hline \multicolumn{5}{|l|}{ Sources } \\
\hline Ordinary users (health field) & $41(32.0)$ & $28(21.9)$ & $53(36.1)$ & $122(31.3)$ \\
\hline Ordinary users (nonhealth field) & $35(27.3)$ & $29(22.7)$ & $40(27.2)$ & $104(26.7)$ \\
\hline Organizations (health field) & $27(21.1)$ & $29(22.7)$ & $21(14.3)$ & 77 (19.7) \\
\hline Organizations (nonhealth field) & $25(19.5)$ & $28(21.9)$ & $33(22.4)$ & $86(22.1)$ \\
\hline \multicolumn{5}{|l|}{ Expression properties } \\
\hline Statistical expression & $54(42.2)$ & $67(52.3)$ & $51(34.7)$ & $172(44.1)$ \\
\hline Nonstatistical expression & $74(57.8)$ & $47(36.7)$ & $96(65.3)$ & $217(55.6)$ \\
\hline \multicolumn{5}{|l|}{ Picture assistance } \\
\hline Yes & $77(60.2)$ & $48(37.5)$ & $75(51.0)$ & $200(51.3)$ \\
\hline No & $51(39.8)$ & $66(51.6)$ & $72(49.0)$ & $189(48.5)$ \\
\hline \multicolumn{5}{|l|}{ Video assistance } \\
\hline Yes & 15 (11.7) & 24 (29.7) & $39(26.5)$ & $78(20.0)$ \\
\hline No & $113(88.3)$ & $90(70.3)$ & $108(73.5)$ & $311(79.7)$ \\
\hline
\end{tabular}

\section{Binary Logistic Regression of the Information Characteristics and Degree of Dissemination}

The influence of each health-promoting message was a dichotomous variable. In this study, we used binary logistic regression to evaluate the impact of framing effects, information sources, expression types, and pictures and videos on the degree of influence of health-promoting messages. The dependent variable of the binary logistic regression model was based on low influence.

We analyzed the 3 focal health message themes and found that the effect of the message characteristics on the message influence did not change with the alteration of the health message themes. For the messages on childhood obesity and cancer, the frame properties and whether the message was a statistical expression had an impact on the message influence.
Compared with loss-framed messages, gain-framed messages had a higher degree of message influence $(P<.001$ in childhood obesity and cancer) and used statistical expressions with a higher degree of message influence $(P=.02$ in childhood obesity, $P<.001$ in cancer). In the messages about smoking, the frame properties (whether statistical expressions or otherwise) and the inclusion or exclusion of videos had an impact on the message influence. Compared with the loss-framed messages, the gain-framed messages had a higher degree of message influence $(P=.03)$. Messages with statistical expressions had a higher degree of message influence than those with nonstatistical expressions $(P=.002)$. Finally, messages with videos had a higher degree of message influence than those without videos $(P=.009)$. The effect of the message characteristics on the influence of messages about childhood obesity, smoking, and cancer can be seen in Tables 2-4. 
Table 2. Binary logistic regression for health-promoting messages regarding childhood obesity.

\begin{tabular}{|c|c|c|c|c|c|}
\hline Parameter & $\beta$ & SE & Wald chi-square $(d f)$ & $\mathrm{OR}^{\mathrm{a}}(95 \% \mathrm{CI})$ & $P$ value \\
\hline \multicolumn{6}{|l|}{ Frame properties } \\
\hline Gain framed & -3.210 & 0.571 & $31.6(1)$ & $0.040(0.013-0.124)$ & $<.001$ \\
\hline Neutral framed & 0.280 & 1.227 & $0.1(1)$ & $1.323(0.119-14.661)$ & .82 \\
\hline Loss framed $\left(\right.$ ref $\left.^{b}\right)$ & $\mathrm{N} / \mathrm{A}^{\mathrm{c}}$ & N/A & N/A & N/A & N/A \\
\hline \multicolumn{6}{|l|}{ Sources } \\
\hline Ordinary users (health field) & -0.072 & 0.739 & $0.0(1)$ & $0.931(0.219-3.962)$ & .92 \\
\hline Ordinary users (nonhealth field) & 0.462 & 0.724 & $0.4(1)$ & $1.587(0.384-6.562)$ & .52 \\
\hline Organizations (health field) & -0.958 & 0.785 & $1.5(1)$ & $0.384(0.082-1.788)$ & .22 \\
\hline Organizations (nonhealth field) (ref) & N/A & N/A & N/A & N/A & N/A \\
\hline \multicolumn{6}{|l|}{ Expression } \\
\hline Statistical expression & -1.227 & 0.525 & $5.5(1)$ & $0.293(0.105-0.820)$ & .02 \\
\hline Nonstatistical expression (ref) & N/A & N/A & N/A & N/A & N/A \\
\hline \multicolumn{6}{|l|}{ Picture assistance } \\
\hline Yes & -0.162 & 0.609 & $0.1(1)$ & $0.850(0.258-2.806)$ & .79 \\
\hline No (ref) & N/A & N/A & N/A & N/A & N/A \\
\hline \multicolumn{6}{|l|}{ Video assistance } \\
\hline Yes & -0.334 & 0.890 & $0.1(1)$ & $0.716(0.125-4.098)$ & .71 \\
\hline No (ref) & N/A & N/A & N/A & N/A & N/A \\
\hline
\end{tabular}

${ }^{\mathrm{a}} \mathrm{OR}$ : odds ratio.

$\mathrm{b}_{\text {ref: reference category. }}$

${ }^{\mathrm{c}} \mathrm{N} / \mathrm{A}$ : not applicable. 
Table 3. Binary logistic regression for health-promoting messages regarding smoking.

\begin{tabular}{|c|c|c|c|c|c|}
\hline Parameter & $\beta$ & SE & Wald chi-square $(d f)$ & $\mathrm{OR}^{\mathrm{a}}(95 \% \mathrm{CI})$ & $P$ value \\
\hline \multicolumn{6}{|l|}{ Frame properties } \\
\hline Gain framed & -1.412 & 0.641 & $4.9(1)$ & $0.244(0.069-0.856)$ & .03 \\
\hline Neutral framed & -0.163 & 1.389 & $0.0(1)$ & $0.850(0.850-12.932)$ & .91 \\
\hline Loss framed (ref ${ }^{\mathrm{b}}$ ) & $\mathrm{N} / \mathrm{A}^{\mathrm{c}}$ & $\mathrm{N} / \mathrm{A}$ & N/A & N/A & N/A \\
\hline \multicolumn{6}{|l|}{ Sources } \\
\hline Ordinary users (health field) & 0.538 & 0.687 & $0.6(1)$ & $1.713(0.446-6.580)$ & .43 \\
\hline Ordinary users (nonhealth field) & 1.209 & 0.747 & $2.6(1)$ & $3.351(0.776-14.475)$ & .11 \\
\hline Organizations (health field) & 0.300 & 0.722 & $0.2(1)$ & $1.350(0.328-5.555)$ & .68 \\
\hline Organizations (nonhealth field) (ref) & $\mathrm{N} / \mathrm{A}$ & N/A & N/A & N/A & N/A \\
\hline \multicolumn{6}{|l|}{ Expression } \\
\hline Statistical expression & -1.932 & 0.609 & $10.1(1)$ & $0.145(0.044-0.478)$ & .002 \\
\hline Nonstatistical expression (ref) & $\mathrm{N} / \mathrm{A}$ & N/A & N/A & N/A & $\mathrm{N} / \mathrm{A}$ \\
\hline \multicolumn{6}{|l|}{ Picture assistance } \\
\hline Yes & -0.879 & 0.631 & $1.9(1)$ & $0.415(0.121-1.429)$ & .16 \\
\hline No (ref) & $\mathrm{N} / \mathrm{A}$ & $\mathrm{N} / \mathrm{A}$ & $\mathrm{N} / \mathrm{A}$ & $\mathrm{N} / \mathrm{A}$ & $\mathrm{N} / \mathrm{A}$ \\
\hline \multicolumn{6}{|l|}{ Video assistance } \\
\hline Yes & -2.016 & 0.767 & $6.9(1)$ & $0.133(0.030-0.599)$ & .009 \\
\hline No (ref) & N/A & N/A & N/A & N/A & N/A \\
\hline
\end{tabular}

${ }^{\mathrm{a} O R}$ : odds ratio.

$\mathrm{b}_{\text {ref: reference category. }}$

${ }^{\mathrm{c}} \mathrm{N} / \mathrm{A}$ : not applicable. 
Table 4. Binary logistic regression for health-promoting messages regarding cancer.

\begin{tabular}{|c|c|c|c|c|c|}
\hline Parameter & $\beta$ & $\mathrm{SE}$ & Wald chi-square $(d f)$ & $\mathrm{OR}^{\mathrm{a}}(95 \% \mathrm{CI})$ & $P$ value \\
\hline \multicolumn{6}{|l|}{ Frame properties } \\
\hline Gain framed & -2.808 & 0.482 & $33.9(1)$ & $0.060(0.023-0.155)$ & $<.001$ \\
\hline Neutral framed & -1.019 & 0.757 & $1.8(1)$ & $0.361(0.082-1.590)$ & .18 \\
\hline Loss framed $\left(\right.$ ref $\left.^{b}\right)$ & $\mathrm{N} / \mathrm{A}^{\mathrm{c}}$ & N/A & N/A & N/A & N/A \\
\hline \multicolumn{6}{|l|}{ Sources } \\
\hline Ordinary users (health field) & 0.671 & 0.587 & $1.3(1)$ & $1.955(0.618-6.183)$ & .25 \\
\hline Ordinary users (nonhealth field) & 0.461 & 0.623 & $0.5(1)$ & $1.586(0.468-5.375)$ & .46 \\
\hline Organizations (health field) & -0.226 & 0.745 & $0.1(1)$ & $0.798(0.185-3.436)$ & .76 \\
\hline Organizations (nonhealth field) (ref) & N/A & N/A & N/A & N/A & N/A \\
\hline \multicolumn{6}{|l|}{ Expression } \\
\hline Statistical expression & -1.714 & 0.473 & $13.1(1)$ & $0.180(0.071-0.455)$ & $<.001$ \\
\hline Nonstatistical expression (ref) & N/A & N/A & N/A & N/A & N/A \\
\hline \multicolumn{6}{|l|}{ Picture assistance } \\
\hline Yes & -0.286 & 0.577 & $0.2(1)$ & $0.751(0.242-2.328)$ & .62 \\
\hline No (ref) & N/A & N/A & N/A & N/A & N/A \\
\hline \multicolumn{6}{|l|}{ Video assistance } \\
\hline Yes & -0.109 & 0.661 & $0.0(1)$ & $0.897(0.245-3.277)$ & .87 \\
\hline No (ref) & N/A & N/A & N/A & N/A & N/A \\
\hline
\end{tabular}

${ }^{\mathrm{a} O R}$ : odds ratio.

$\mathrm{b}_{\text {ref: reference category. }}$

${ }^{\mathrm{c}} \mathrm{N} / \mathrm{A}$ : not applicable.

\section{Discussion}

\section{Principal Results}

To the best of our knowledge, this study has broken new ground in two aspects by (1) exploring the application of framing effects in social media and (2) providing ideas for drafting health-promoting messages with a high degree of influence.

First, the use of gain-framed messages in the health themes of childhood obesity $(P<.001)$, smoking $(P=.03)$, and cancer $(P<.001)$ can significantly improve the influence of health-promoting messages (Table 2). Rothman and Salovey [46] and Rothman et al [47] divided health behaviors into prevention and detection behaviors according to the risk perception of individuals. Preventive behaviors include exercise, quitting smoking, eating healthy, and using sunscreen. They believed that gain-framed messages were more persuasive in promoting disease prevention behaviors. Goal-framing effects based on prospect theory have also revealed that factually equivalent messages have different levels of persuasiveness depending on the frame adopted by the messages [48]. Gallagher and Updegraff [49] believed that gain-framed health-promoting messages stimulated more information processing and better subsequent memory. Furthermore, many previous investigations support our conclusion. A cross-sectional study of 592 caregivers of preschool children found that gain-framed messages could significantly improve the acceptance of information by caregivers [25]. Romanowich and Lamb [50] posited that health education using gain-framed messages could be more useful for nonsmokers. A qualitative survey of African American adolescents by Satia et al [51] indicated greater consistency with gain-framed cancer prevention messages. Most research on the framing effects of health-promoting messages have been conducted by questionnaires or interviews [15]. However, the real world involves people observing information and making decisions in a complex environment [52]. This study further confirmed that gain-framed messages are a favorable strategy in the dissemination of health-promoting messages in everyday life.

Second, the use of statistical expression in the health themes of childhood obesity $(P=.02)$, smoking $(P=.002)$, and cancer $(P<.001)$ can significantly improve the influence of health-promoting messages (Table 2). Statistical expressions refer to health-promoting messages with numerical content [53]. Nonstatistical expressions denote health-promoting messages without any precise numbers and are usually used in the description of examples and stories [53]. No conclusion has been reached about the persuasiveness of these two expression types [34]. A meta-analysis [23] and an investigation of 1270 participants [54] found that statistical messages were more convincing than narrative ones. A message that combines narrative and statistical expression is more convincing than one using either narrative or statistical expression alone. We hypothesized that adding statistical expressions to 
health-promoting messages when describing health behaviors and consequences could create more active engagement toward those messages and earn them more retweets, comments, and likes. Another meta-analysis also revealed that statistical expression has a stronger impact on beliefs and attitudes than narrative expression and that statistical expressions, beliefs, and attitudes are mainly related to cognitive responses [55]. Wong et al [39] combined numerical framing effects and prospect theory and verified that precise numbers could more easily represent the probability of risk. We believe this finding may explain why people pay more attention to health-promoting messages that contain statistical expressions.

Third, the use of videos significantly improved the influence of health-promoting messages only for messages regarding smoking $(P=.009)$. A review suggested that compared with text alone, adding pictures that are closely related to the written text can significantly improve the attention to and recall of health education information [56]. However, Houts et al [56] noted that great care should be taken when including picture materials in health messages so that the audiences can understand the key points of the message without being distracted by irrelevant details. Levie and Lentz [57] posited that pictures not closely related to the text have no beneficial effect on comprehension. Furthermore, the impact of using videos on health-promoting messages may be uncertain. Occa and Suggs [58] found that videos had a positive impact when communicating breast cancer information to 194 Italian women. Conversely, Xie [59] suggested that there was no significant difference in risk perception caused by words and sounds. We suggest that publishers add appropriate pictures and videos as much as possible when making health-promoting messages.

Fourth, we believe that accounts from organizations in health fields should release health-promoting messages more actively. People tend to trust universities and official institutions more than other types of organizations [60]. Furthermore, people consider private doctors, medical universities, and governments the most trusted sources of health messages $[44,45]$. As shown in Table 1, the proportion of accounts from individual users was higher than for organizational users, and users engaged in the health field outnumbered those in nonhealth fields. Specific audiences are more willing to believe that the most reliable information is provided by accounts from a health field [24]. Thus, ordinary users and organizations from health fields must participate in the dissemination of health-promoting messages.

Fifth, we found that health-promoting messages account for a very small proportion of the social media posts related to the 3 health themes. We thought this may be related to four main reasons. First, the definition of a health-promoting message was a message that included both health behaviors and health outcomes [15], so we excluded some messages, such as messages only referring to the cause of a disease. Second, in a health topic, the amount of social content was often much larger than the amount of health professional content [61]. Third, we found that the celebrity effect exists in Weibo health themes. If a celebrity died of cancer, there would soon be a lot of cancer-related messages on Weibo. However, there was a lack of clear health guidance in these messages. We excluded a lot of these kinds of eye-catching messages. Fourth, even under the theme of health, a lot of messages on social media were still related to advertising [62]. We excluded the messages that contained advertising. This result reflects reality. There were few health-promoting messages published on Weibo about childhood obesity, smoking, and cancer. In the health field, many researchers have confirmed that health-promoting messages using framing effects can stimulate people's health awareness [63] and improve their willingness to prevent and treat health conditions [20,49]. Health promotion messages including health behaviors and health outcomes should be widely used. Our research suggests that professionals in health fields should be more active in publishing health-promoting messages on social media.

\section{Limitations}

This study has several limitations. First, a small sample size was analyzed in this work. We needed to explore the impact of goal-framing effects on the influence of health-promoting messages. Accordingly, we included only health-promoting messages, such as those about behaviors and consequences [15], thereby limiting the writing template for such messages. This approach did not fully incorporate all health messages and may have produced errors. Moreover, this research only focused on certain health-promoting messages to fill the gaps in the literature. Second, we formulated the definition of a Weibo message's degree of influence according to the literature [41,42] and from expert advice, and we used only 3 indexes: retweets, comments, and likes. The number of users who viewed a message is an excellent index to evaluate the degree of influence, but restrictions of the Weibo platform meant that we could not ascertain the number of views for every message. If the Weibo platform cancels this restriction in the future, then views should be included in the evaluation index. Third, we did not evaluate whether the pictures and videos added in the Weibo health-promoting messages accurately matched the points of the message. Such an omission may have affected our results. We still suggest that the publisher add appropriate pictures and videos as much as possible to health-promoting messages. In the future, researchers can further examine the impact of pictures and videos on health-promoting messages on social media.

\section{Conclusions}

In this study, we identified the factors that could affect the degree of influence of health-promoting messages on the Sina Weibo platform. A total of 389 health-promoting messages were included in this work. The use of gain-framed messages and statistical expressions could improve the influence of messages for all 3 themes (ie, childhood obesity, smoking, and cancer). Although adding pictures and videos to messages did not significantly improve the influence of messages about childhood obesity and cancer, we still contend that adding appropriate pictures and videos as much as possible when producing health-promoting messages is a good strategy. We encourage users from organizations in health fields to release more health-promoting messages. When public health institutions and professionals release such messages, the framework, organization, and content of the messages must be considered. In this way, health-promoting messages may become more influential. 


\section{Acknowledgments}

This research was funded by the Student Research and Innovation Experiment Project of the College of Medical Informatics, Chongqing Medical University, China (grant number 2019C002); the Special Research Project of Philosophy and Social Science of Chongqing Medical University, China (grant number 201712); the Intelligent Medicine Research Project of Chongqing Medical University in 2019 (ZHYX2019006); the Chinese Scholarship Council of the Ministry of Education (grant number 201808505165); and the Ministry of Education in China's Project of Humanities and Social Sciences (research on the mechanism and intervention countermeasures of framing effects in the formation of adolescent health literacy No. 20YJCZH043). The funders had no role in the design of the study; the collection, analyses, or interpretation of data; the writing of the manuscript; or the decision to publish the results.

\section{Authors' Contributions}

$\mathrm{XH}$ and $\mathrm{QR}$ designed the experiments. QR and ZZ performed the experiments. QR analyzed the data. YL helped analyze the data. XH, YZ, LB, and ZZ helped draft the manuscript. All authors read and approved the final manuscript.

\section{Conflicts of Interest}

None declared.

\section{Multimedia Appendix 1}

Coding principle for the health-promoting messages.

[DOCX File, 18 KB-Multimedia Appendix 1]

\section{References}

1. Yang F, Wendorf Muhamad J, Yang Q. Exploring Environmental Health on Weibo: A Textual Analysis of Framing Haze-Related Stories on Chinese Social Media. Int J Environ Res Public Health 2019 Jul 04;16(13) [FREE Full text] [doi: 10.3390/ijerph16132374] [Medline: $\underline{31277378]}$

2. China Internet Information Center. The 44th Statistical Report on the Development of Internet in China 2019. China Internet Information Center. URL: http://www.cnnic.net.cn/hlwfzyj/hlwxzbg/hlwtjbg/201908/P020190830356787490958.pdf [accessed 2020-02-20]

3. Moorhead SA, Hazlett DE, Harrison L, Carroll JK, Irwin A, Hoving C. A new dimension of health care: systematic review of the uses, benefits, and limitations of social media for health communication. J Med Internet Res 2013 Apr 23;15(4):e85 [FREE Full text] [doi: 10.2196/jmir.1933] [Medline: 23615206]

4. Pagoto S, Waring ME, Xu R. A Call for a Public Health Agenda for Social Media Research. J Med Internet Res 2019 Dec 19;21(12):e16661 [FREE Full text] [doi: 10.2196/16661] [Medline: 31855185]

5. Yaya S, Uthman O, Amouzou A, Bishwajit G. Mass media exposure and its impact on malaria prevention behaviour among adult women in sub-Saharan Africa: results from malaria indicator surveys. Glob Health Res Policy 2018;3:20 [FREE Full text] [doi: 10.1186/s41256-018-0075-x] [Medline: 29998191]

6. The White Book of Chinese Weibo's Market. Sina Weibo. 2019. URL: http://data.weibo.com/report/reportDetail?id=433 [accessed 2020-09-07]

7. Alhabash S, McAlister AR. Redefining virality in less broad strokes: Predicting viral behavioral intentions from motivations and uses of Facebook and Twitter. 2014 Feb 24;17(8):1317-1339. [doi: 10.1177/1461444814523726]

8. Brooke C. Critique of Information. 2003 Mar;16(1):111-114. [doi: 10.1108/itp.2003.16.1.111.1]

9. Chou WS, Hunt YM, Beckjord EB, Moser RP, Hesse BW. Social media use in the United States: implications for health communication. J Med Internet Res 2009 Nov 27;11(4):e48 [FREE Full text] [doi: 10.2196/jmir. 1249] [Medline: 19945947]

10. Jiang S, Beaudoin CE. Smoking Prevention in China: A Content Analysis of an Anti-Smoking Social Media Campaign. J Health Commun 2016 Jul;21(7):755-764. [doi: 10.1080/10810730.2016.1157653] [Medline: 27232655]

11. Wang S, Paul MJ, Dredze M. Social media as a sensor of air quality and public response in China. J Med Internet Res 2015 Mar 26;17(3):e22 [FREE Full text] [doi: 10.2196/jmir.3875] [Medline: 25831020]

12. Guo Y, Goh DH. "I Have AIDS": Content analysis of postings in HIV/AIDS support group on a Chinese microblog. Computers in Human Behavior 2014 May;34:219-226. [doi: 10.1016/j.chb.2014.02.003]

13. Adams SA. Revisiting the online health information reliability debate in the wake of "web 2.0": an inter-disciplinary literature and website review. Int J Med Inform 2010 Jun;79(6):391-400. [doi: 10.1016/j.ijmedinf.2010.01.006] [Medline: 20188623]

14. Jackson L. Information Complexity and Medical Communication: The Effects of Technical Language and Amount of Information in a Medical Message. Health Communication 1992 Jul;4(3):197-210. [doi: 10.1207/s15327027hc0403 3] 
15. Van 't Riet J, Cox AD, Cox D, Zimet GD, De Bruijn G, Van den Putte B, et al. Does perceived risk influence the effects of message framing? Revisiting the link between prospect theory and message framing. Health Psychol Rev 2016 Dec;10(4):447-459. [doi: 10.1080/17437199.2016.1176865] [Medline: 27062974]

16. McCray AT. Promoting health literacy. J Am Med Inform Assoc 2005;12(2):152-163. [doi: 10.1197/jamia.M1687] [Medline: 15561782]

17. Shi J, Mao A, Liu C, Dong P, Ren J, Wang K, et al. [Health literacy and awareness of cancer control in urban China, 2005-2017: overall design of a national multicenter survey]. Zhonghua Yu Fang Yi Xue Za Zhi 2020 Jan 06;54(1):108-112. [doi: 10.3760/cma.j.issn.0253-9624.2020.01.020] [Medline: 31914578]

18. Cao W, Zhang X, Xu K, Wang Y. Modeling Online Health Information-Seeking Behavior in China: The Roles of Source Characteristics, Reward Assessment, and Internet Self-Efficacy. Health Commun 2016 Sep;31(9):1105-1114. [doi: 10.1080/10410236.2015.1045236] [Medline: 26861963]

19. Dunn HK, Pearlman DN, Beatty A, Florin P. Psychosocial Determinants of Teens' Online Engagement in Drug Prevention Social Media Campaigns: Implications for Public Health Organizations. J Prim Prev 2018 Oct;39(5):469-481. [doi: 10.1007/s10935-018-0522-y] [Medline: $\underline{30194518]}$

20. Myers R. Promoting healthy behaviors: how do we get the message across? Int J Nurs Stud 2010 Apr;47(4):500-512. [doi: 10.1016/j.ijnurstu.2009.11.017] [Medline: 20031126]

21. Meppelink CS, van Weert JCM, Haven CJ, Smit EG. The effectiveness of health animations in audiences with different health literacy levels: an experimental study. J Med Internet Res 2015 Jan 13;17(1):e11 [FREE Full text] [doi: 10.2196/jmir.3979] [Medline: 25586711]

22. Meppelink CS, Smit EG, Buurman BM, van Weert JCM. Should We Be Afraid of Simple Messages? The Effects of Text Difficulty and Illustrations in People With Low or High Health Literacy. Health Commun 2015;30(12):1181-1189. [doi: 10.1080/10410236.2015.1037425] [Medline: 26372031]

23. Allen M, Preiss RW. Comparing the persuasiveness of narrative and statistical evidence using meta - analysis. Communication Research Reports 1997 Mar;14(2):125-131. [doi: 10.1080/08824099709388654]

24. Sundar SS. The MAIN Model: A Heuristic Approach to Understanding Technology Effects on Credibility. In: Metzger MJ, Flanagin AJ, editors. Digital Media, Youth, and Credibility. Cambridge, MA: MIT Press; 2008:73-100.

25. Rao Q, Bai L, Lv Y, Abdullah AS, Brooks I, Xie Y, et al. Goal-Framing and Temporal-Framing: Effects on the Acceptance of Childhood Simple Obesity Prevention Messages among Preschool Children's Caregivers in China. Int J Environ Res Public Health 2020 Jan 26;17(3):1-15 [FREE Full text] [doi: 10.3390/ijerph17030770] [Medline: 31991873]

26. Zhang D, Gu J, Shao R. A Cluster Analysis of College Students' Health Information Acquisition Channels: Active Seeking and Accidental Exposure. Chin J Journalism Commun 2015 May;37(05):81-93. [doi: 10.13495/j.cnki.cjjc.2015.05.006]

27. Kahneman D, Tversky A. Prospect Theory: An Analysis of Decision under Risk. Econometrica 1979 Mar;47(2):263. [doi: $10.2307 / 1914185]$

28. Striegel-Moore RH, Thompson DR, Affenito SG, Franko DL, Barton BA, Schreiber GB, et al. Fruit and vegetable intake: Few adolescent girls meet national guidelines. Prev Med 2006 Mar;42(3):223-228. [doi: 10.1016/j.ypmed.2005.11.018] [Medline: 16406116 ]

29. van 't Riet J, Ruiter RAC, Werrij MQ, de Vries H. Investigating message-framing effects in the context of a tailored intervention promoting physical activity. Health Educ Res 2010 Apr;25(2):343-354. [doi: 10.1093/her/cyp061] [Medline: $\underline{19841041]}$

30. Iannotti RJ, Finney LJ, Sander AA, De Leon JM. Effect of clinical breast examination training on practitioner's perceived competence. Cancer Detection and Prevention 2002 May;26(2):146-148. [doi: 10.1016/s0361-090x(02)00029-6]

31. Edwards A, Elwyn G, Covey J, Matthews E, Pill R. Presenting risk information--a review of the effects of "framing" and other manipulations on patient outcomes. J Health Commun 2001;6(1):61-82. [doi: 10.1080/10810730150501413] [Medline: $11317424]$

32. Fung IC, Cai J, Hao Y, Ying Y, Chan BSB, Tse ZTH, et al. Global Handwashing Day 2012: a qualitative content analysis of Chinese social media reaction to a health promotion event. Western Pac Surveill Response J 2015;6(3):34-42 [FREE Full text] [doi: 10.5365/WPSAR.2015.6.2.003] [Medline: 26668765]

33. Kahneman D, Tversky A. On the psychology of prediction. Psychol Rev 1973;80(4):237-251. [doi: 10.1037/h0034747]

34. Limon MS, Kazoleas DC. A comparison of exemplar and statistical evidence in reducing counter - arguments and responses to a message. Communication Research Reports 2004 Jun;21(3):291-298. [doi: 10.1080/08824090409359991]

35. Reinard JC. The Empirical Study of the Persuasive Effects of Evidence: The Status After Fifty Years of Research. Human Comm Res 1988 Sep;15(1):3-59. [doi: 10.1111/j.1468-2958.1988.tb00170.x]

36. Li J, Xu Q, Cuomo R, Purushothaman V, Mackey T. Data Mining and Content Analysis of the Chinese Social Media Platform Weibo During the Early COVID-19 Outbreak: Retrospective Observational Infoveillance Study. JMIR Public Health Surveill 2020 Apr 21;6(2):e18700 [FREE Full text] [doi: 10.2196/18700] [Medline: 32293582]

37. Bai L, Cai Z, Lv Y, Wu T, Sharma M, Shi Z, et al. Personal Involvement Moderates Message Framing Effects on Food Safety Education among Medical University Students in Chongqing, China. Int J Environ Res Public Health 2018 Sep 19;15(9) [FREE Full text] [doi: 10.3390/ijerph15092059] [Medline: 30235903] 
38. Suka M, Yamauchi T, Yanagisawa H. Comparing responses to differently framed and formatted persuasive messages to encourage help-seeking for depression in Japanese adults: a cross-sectional study with 2-month follow-up. BMJ Open 2018 Nov 12;8(11):e020823. [doi: 10.1136/bmjopen-2017-020823] [Medline: 30420341]

39. Wong K, Kwong J. Comparing two tiny giants or two huge dwarfs? Preference reversals owing to number size framing. Organizational Behavior and Human Decision Processes 2005 Sep;98(1):54-65 [FREE Full text] [doi: 10.1016/j.obhdp.2005.04.002]

40. Liu X, Lu J, Wang H. When Health Information Meets Social Media: Exploring Virality on Sina Weibo. Health Commun 2017 Dec;32(10):1252-1260. [doi: 10.1080/10410236.2016.1217454] [Medline: 27668831]

41. Shiratuddin N, Hassan S, Hashim N, Sakdan M, Sajat M. Blog influence index: A measure of influential weblog. Int J Virtual Communities Soc Netw 2011;3(3):35-45. [doi: 10.4018/jvcsn.2011070103]

42. Hassan S, Shiratuddin N. Identifying criteria for measuring influence of social media. International Journal of Interactive Communication Systems and Technologies 2013;10(3):91. [doi: 10.5555/2820186.2820189]

43. Starbird K, Palen L. Pass it on?: Retweeting in mass emergency. 2010 Presented at: 7th International ISCRAM Conference; May 2010; Seattle, WA.

44. Xiong X, Zhou G, Huang Y, Ma J. Predicting Popularity of Tweets on Sina Weibo. J Inf Eng Univ 2012;13(4):496-502.

45. Wu H. Research on Active Microblog Prediction Based on LDA and Random Forest Model [In China]. Hefei University of Technology 2017.

46. Rothman AJ, Salovey P. Shaping perceptions to motivate healthy behavior: the role of message framing. Psychol Bull 1997 Jan;121(1):3-19. [doi: 10.1037/0033-2909.121.1.3] [Medline: 9000890]

47. Rothman AJ, Salovey P, Antone C, Keough K, Martin CD. The Influence of Message Framing on Intentions to Perform Health Behaviors. Journal Exp Soc Psychol 1993 Sep;29(5):408-433. [doi: 10.1006/jesp.1993.1019]

48. Levin IP, Schneider SL, Gaeth GJ. All Frames Are Not Created Equal: A Typology and Critical Analysis of Framing Effects. Organ Behav Hum Decis Process 1998 Nov;76(2):149-188. [doi: 10.1006/obhd.1998.2804] [Medline: 9831520]

49. Gallagher KM, Updegraff JA. Health message framing effects on attitudes, intentions, and behavior: a meta-analytic review. Ann Behav Med 2012 Feb;43(1):101-116. [doi: 10.1007/s12160-011-9308-7] [Medline: 21993844]

50. Romanowich P, Lamb RJ. The effect of framing incentives as either losses or gains with contingency management for smoking cessation. Addict Behav 2013 Apr;38(4):2084-2088 [FREE Full text] [doi: 10.1016/j.addbeh.2013.01.007] [Medline: 23403276]

51. Satia JA, Barlow J, Armstrong-Brown J, Watters JL. Qualitative Study to Explore Prospect Theory and Message Framing and Diet and Cancer Prevention-Related Issues Among African American Adolescents. Cancer Nursing 2010;33(2):102-109. [doi: 10.1097/ncc.0b013e3181be5e8a]

52. Sanders Thompson VL. Making decisions in a complex information environment: evidential preference and information we trust. BMC Med Inform Decis Mak 2013;13 Suppl 3:S7 [FREE Full text] [doi: 10.1186/1472-6947-13-S3-S7] [Medline: 24565305]

53. Han B, Fink EL. How Do Statistical and Narrative Evidence Affect Persuasion?: The Role of Evidentiary Features. Argumentation and Advocacy 2017 Feb 02;49(1):39-58. [doi: 10.1080/00028533.2012.11821779]

54. Allen M, Bruflat R, Fucilla R, Kramer M, McKellips S, Ryan D, et al. Testing the persuasiveness of evidence: Combining narrative and statistical forms. Communication Research Reports 2000 Sep;17(4):331-336. [doi: $10.1080 / 08824090009388781]$

55. Zebregs S, van den Putte B, Neijens P, de Graaf A. The differential impact of statistical and narrative evidence on beliefs, attitude, and intention: a meta-analysis. Health Commun 2015;30(3):282-289. [doi: 10.1080/10410236.2013.842528] [Medline: 24836931]

56. Houts P, Doak C, Doak L, Loscalzo M. The role of pictures in improving health communication: a review of research on attention, comprehension, recall, and adherence. Patient Educ Couns 2006 May;61(2):173-190. [doi:

10.1016/j.pec.2005.05.004] [Medline: 16122896]

57. Levie W, Lentz R. Effects of text illustrations: A review of research. Edu Tech Res Dev 1982;30(4):232. [doi: 10.1007/BF02765184]

58. Occa A, Suggs L. Communicating Breast Cancer Screening With Young Women: An Experimental Test of Didactic and Narrative Messages Using Video and Infographics. J Health Commun 2016;21(1):1-11. [doi: 10.1080/10810730.2015.1018611] [Medline: 26147625]

59. Xie X. How Can a Risk Be Increased? An Analysis of Risk Communication Channels. Acta Psychologica Sinica 2008 Sep 19;40(4):456-465. [doi: 10.3724/sp.j.1041.2008.00456]

60. Briggs P, Burford B, De Angeli A, Lynch P. Trust in Online Advice. Social Science Computer Review 2016 Aug 18;20(3):321-332. [doi: 10.1177/089443930202000309]

61. Unger JB, Escobedo P, Allem J, Soto DW, Chu K, Cruz T. Perceptions of Secondhand E-Cigarette Aerosol Among Twitter Users. Tob Regul Sci 2016 Apr;2(2):146-152 [FREE Full text] [doi: 10.18001/TRS.2.2.5] [Medline: 28090560]

62. Freeman B, Chapman S. Is "YouTube" telling or selling you something? Tobacco content on the YouTube video-sharing website. Tob Control 2007 Jun;16(3):207-210. [doi: 10.1136/tc.2007.020024] [Medline: 17565142] 
63. O'Connor AM, Pennie RA, Dales RE. Framing effects on expectations, decisions, and side effects experienced: the case of influenza immunization. J Clin Epidemiol 1996 Nov;49(11):1271-1276. [doi: 10.1016/s0895-4356(96)00177-1] [Medline: $\underline{8892495]}$

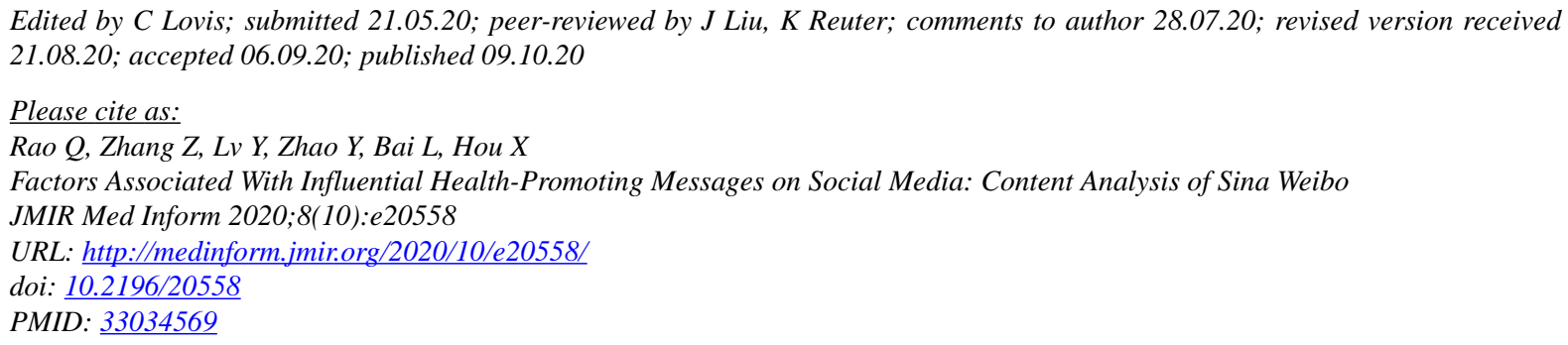

(C) Qingmao Rao, Zuyue Zhang, Yalan Lv, Yong Zhao, Li Bai, Xiaorong Hou. Originally published in JMIR Medical Informatics (http://medinform.jmir.org), 09.10.2020. This is an open-access article distributed under the terms of the Creative Commons Attribution License (https://creativecommons.org/licenses/by/4.0/), which permits unrestricted use, distribution, and reproduction in any medium, provided the original work, first published in JMIR Medical Informatics, is properly cited. The complete bibliographic information, a link to the original publication on http://medinform.jmir.org/, as well as this copyright and license information must be included. 